\title{
The Study of Effect of Pomegranate Juice on Type 2 Diabetes Mellietus
}

\author{
Dr. K.Jyothsna \\ Department of Pharmacology, Bhaskar Medical College, Yenkapally (V), Moinabad(M), Ranga Reddy district, \\ Telangana -500075
}

\begin{abstract}
Over the last decade, various studies have linked pomegranate (Punica granatum Linn), a fruit native to the Middle East, with type 2diabetes prevention and treatment. This article focuses on current laboratory and clinical research related to the effects of pomegranate fractions (peels, flowers, and seeds) and some of their active components on biochemical and metabolic variables associated with the pathologic markers of type 2 diabetes. This review systematically presents findings from cell culture and animal studies as well as clinical human research. One key mechanism by which pomegranate fractions affect the type 2 diabetic condition is by reducing oxidative stress and lipid peroxidation. This reduction may occur by directly neutralizing the generated reactive oxygen species, increase in certain antioxidant enzyme activities. Fasting blood glucose levels were decreased significantly by punicic acid, methanolic seed extract, and pomegranate peel extract
\end{abstract}

Keywords: Type 2 diabetes, pomegranate, fasting blood glucose, punicic acid

\section{Introduction}

Diabetes prevention and treatment are high priorities in medical research. Fruit extracts have been used extensively in this context because they are natural, safe, and readily available. The fruit is pomegranate (Punica granatum Linn) (Family Punicaceae), a fruit native to the Middle East [1]. Different parts of this plant are used in indigenous Indian medicine to cure various diseases, particularly diabetes [2]. Pomegranate fractions from different parts of the fruit have been linked with the prevention and treatment of a wide range of disorders and diseases, including cardiovascular disease, cancer, Alzheimer disease, erectile dysfunction, male infertility, arthritis, brain ischemia, dental diseases, obesity, and diabetes [3] and [4]. The therapeutic potential of pomegranate fractions is due to the presence of unique bioactive compounds with antioxidant, antiinflammatory, anti-infective, anti-atherogenic, anti-carcinogenic, and anti-hyperglycemic effects [4], [5] and [6]. The connection between pomegranate and diabetes was discussed by Katz et al, 2007 [7]. Katz and his group concluded that pomegranate extracts and their active compounds could be effective in the treatment and prevention of type 2 diabetes. Later reviews that addressed the therapeutic effects of pomegranate in general [3] or the cardioprotective benefits of pomegranate juice [8] have indirectly discussed the link between pomegranate and diabetes. More recently, a review by Medjakovic and Jungbauer (2013) focused on the potential use of pomegranate and its compounds in therapy for metabolic syndrome [4].

\section{Methods}

It is comparative, open labeled, cohort study conducted in regional center, Bhaskar Medical college, yenkapally village, moinabad mandal, Hyderabad, Telagana. It was conducted from jun 2016 to oct 2016. It was conducted between two groups of patients has taken Pomogranate juice 50g/d from seeds, 20 patients has taken juice from seeds for 3 months period without adverse effects. It was compared lab tests like total cholesterol, LDL cholesterol, blood glucose levels. Two groups are compared by paired t-test, standard deviation and Pvalue

\section{Results}

Diabetic patients are taken as 2 groups one who has taken Pomegranate seed juice at the time of beginning of study, another same groups at 3 months, Paired t-test perfomed, p- value taken as acceptable.

Pomegranate juice effect on different parameters

\begin{tabular}{|l|l|l|l|}
\hline Parameter & $\begin{array}{l}\text { Beginning } \\
\text { Mean } \pm \text { SD }\end{array}$ & $\begin{array}{l}3 \text { months } \\
\text { Mean } \pm \text { SD }\end{array}$ & p-value \\
\hline Number of patients & 40 & 20 & \\
\hline Fasting Blood Sugar & $120 \pm 5 \mathrm{mg} / \mathrm{dl}$ & $107 \pm 4 \mathrm{mg} / \mathrm{dl}$ & $0.05^{*}$ \\
\hline Hbs mg/dl & $20 \pm 2 \mathrm{mg} / \mathrm{dl}$ & $15 \pm 1.5 \mathrm{mg} / \mathrm{dl}$ & $0.05^{*}$ \\
\hline Total Cholesterol mg/dl & $150 \pm 11 \mathrm{mg} / \mathrm{dl}$ & $110 \pm 10 \mathrm{mg} / \mathrm{dl}$ & $0.05^{*}$ \\
\hline LDL mg/dl & $120 \pm 15 \mathrm{mg} / \mathrm{dl}$ & $110 \pm 10 \mathrm{mg} / \mathrm{dl}$ & $0.05^{*}$ \\
\hline
\end{tabular}

Table 1:*p.value $<0.05$ is acceptable. LDL=Low denisity lipoproteins 


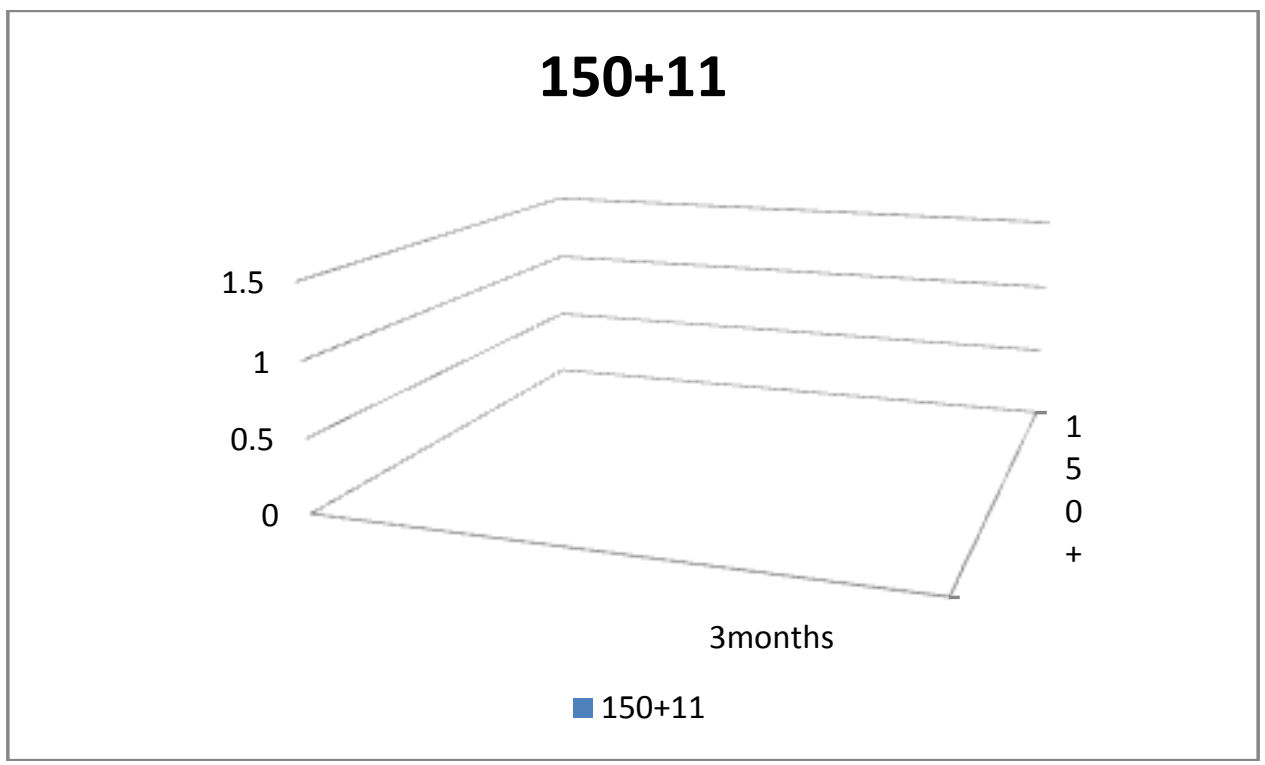

Fig.1

\section{Discussion}

Pomegranate extracts and their active components have great medical potential as they may provide an effective and safe treatment for type 2 diabetes and its pathological concerns. They affect the type 2 diabetic condition, mainly by antagonizing the damaging effects of ROS[8].

The levels of fasting blood glucose were only decreased by punicic acid, methanolic seed extract, and pomegranate peel extract. Known components in pomegranate (punicalagin and ellagic, gallic, oleanolic, ursolic, and uallic acids) were found to have anti-diabetic effects [9]. Furthermore, pomegranate juice had a potential impact on type 2 diabetes variables due to its antioxidant polyphenolic tannins and anthocyanins. There is decrease in total cholesterol and LDL (Low Density Lipoproteins)[10].

Pomegranate is consumed worldwide; however, a large knowledge gap still exists regarding its use for the clinical management of type 2 diabetes[11][12]. Therefore, further research on the effect of pomegranate components needs to be performed to fully characterize the relationship between this fruit, flower and type 2 diabetes[13]. Our lab is currently conducting a clinical study on the short-term effects of pomegranate juice consumption on fasting blood glucose and its regulating hormones showed that there is decrease in Diabetes Type 2 [14].

\section{Conclusion}

There were decrease in blood sugar level, total cholesterol and LDL in type 2 diabetic patients who has taken Pomegranate juice.Hence it can be recommended to take this juice.

\section{Acknowledgement}

It is thanks to given opportunity to conduct study in Bhaskar Medical College. It was thanks to has given great opportunity to conduct and providing clinical material especially for staff.

\section{References}

[1]. S.D. Johanningsmeier, G.K. Harris Pomegranate as a functional food and nutraceutical source Annu Rev Food Sci Technol, 2 (2011), pp. 181-201

[2]. A.K. Das, S.C. Mandal, S.K. Banerjee, S. Sinha, B.P. Saha, M. Pal Studies on the hypoglycaemic activity of Punica granatum seed in streptozotocin induced diabetic rats Phytother Res, 15 (2001), pp. 628-629

[3]. J.S. Jurenka .Therapeutic applications of pomegranate (Punica granatum L.): a review. Altern Med Rev, 13 (2008), pp. 128144

[4]. S. Medjakovic, A. Jungbauer. Pomegranate: a fruit that ameliorates metabolic syndrome. Food Funct, 4 (2013), pp. 19-39

[5]. T. Ismail, P. Sestili, S. Akhtar. Pomegranate peel and fruit extracts: a review of potential anti-inflammatory and antiinfective effects. J Ethnopharmacol, 143 (2012), pp. 397-405

[6]. G. Trottier, P.J. Bostrom, N. Lawrentschuk, N.E. Fleshner. Nutraceuticals and prostate cancer prevention: a current review. Nat Rev Urol, 7 (2010), pp. 21-30.

[7]. S.R. Katz, R.A. Newman, E.P. Lansky Punica granatum: heuristic treatment for diabetes mellitus .J Med Food, 10 (2007), pp. 213-217

[8]. A. Basu, K. Penugonda. Pomegranate juice: a heart-healthy fruit juice. Nutr Rev, 67 (2009), pp. 49-56.

[9]. N. Li, M. Karin. Is NF-kappaB the sensor of oxidative stress?. FASEB J, 13 (1999), pp. 1137-1143

[10]. S.Y. Schubert, I. Neeman, N. Resnick. A novel mechanism for the inhibition of NF-kappaB activation in vascular endothelial cells by natural antioxidants. FASEB J, 16 (2002), pp. 1931-1933. 
[11]. B.B. Aggarwal, S. Shishodia. Suppression of the nuclear factor-kappaB activation pathway by spice-derived phytochemicals: reasoning for seasoning. Ann N Y Acad Sci, 1030 (2004), pp. 434-441.

[12]. T.H. Huang, G. Peng, B.P. Kota, G.Q. Li, J. Yamahara, B.D. Roufogalis, et al. Anti-diabetic action of Punica granatum flower extract: activation of PPAR-gamma and identification of an active component. Toxicol Appl Pharmacol, 207 (2005), pp. 160169.

[13]. H.S. Parmar, A. Kar. Medicinal values of fruit peels from Citrus sinensis, Punica granatum, and Musa paradisiaca with respect to alterations in tissue lipid peroxidation and serum concentration of glucose, insulin, and thyroid hormones. $\mathrm{J}$ Med Food, 11 (2008), pp. 376-381.

[14]. R. Hontecillas, M. O'Shea, A. Einerhand, M. Diguardo, J. Bassaganya-Riera Activation of PPAR gamma and alpha by punicic acid ameliorates glucose tolerance and suppresses obesity-related inflammation. J Am Coll Nutr, 28 (2009), pp. 184-195 